\title{
RIQUEZA ESPECÍFICA EM ÁREAS DE CAMPO NATIVO IMPACTADAS POR VISITAÇÃO TURÍSTICA E PASTEJO NO PARQUE NACIONAL DOS CAMPOS GERAIS, PR
}

\author{
Karine Dalazoana ${ }^{1}$, Rosemeri Segecin Moro ${ }^{2}$ \\ ${ }^{1}$ Bióloga, M.Sc., Depto. de Geociências, UEPG, Ponta Grossa, PR, Brasil - karine.bio@ibest.com.br \\ ${ }^{2}$ Bioquímica, Dr ${ }^{\mathrm{a}}$, Depto. de Biologia Geral, UEPG, Ponta Grossa, PR, Brasil - moro.uepg@ gmail.com \\ Recebido para publicação: 08/06/2009 - Aceito para publicação: 25/10/2010
}

\begin{abstract}
Resumo
O Parque Nacional dos Campos Gerais (PNCG) detém áreas de campos de altitude sob forte pressão antrópica, com a expansão das atividades agrícolas, pecuária, silvicultura e visitação turística desordenada. Devido ao impacto gerado, existe uma tendência à diminuição da riqueza específica, através da seletividade de espécies. Este trabalho analisa a resposta das comunidades campestres em termos de composição de espécies aos impactos de pastejo, roçada e pisoteio humano. Em quatro estações de coleta, foram determinados 107 táxons distribuídos em 23 famílias botânicas. As famílias com maior riqueza específica foram Asteraceae e Poaceae, ambas com 24 táxons, e Fabaceae, com 14 táxons. A riqueza específica variou de 27 a 75 espécies, com maior riqueza na estação não pastejada nem roçada, apenas visitada por turistas. $\mathrm{O}$ levantamento mostrou que, apesar da pressão antrópica, as áreas estudadas exibem considerável riqueza específica quando comparadas a outros trabalhos na região, mantendo ainda seu potencial biótico dinâmico. Floristicamente, os impactos gerados por gado ou por manejo com roçadeira se equivalem. Seis gêneros têm potencial para serem utilizados como bioindicadores de áreas conservadas: Croton, Galactia, Periandra, Cuphea, Pavonia e Commelina, mas há necessidade de ampliação das áreas estudadas para estabelecer mais claramente seu valor de bioindicação.

Palavras-chave: Campo nativo; Campos Gerais; área impactada; pastejo; visitação turística.
\end{abstract}

\begin{abstract}
The species diversity in native grassland areas that are under impact of tourism and grazing at Campos Gerais National Park, Parana, Brazil. Campos Gerais National Park (PNCG) has areas of grassland under high anthropogenic pressure, as expansion of agricultural activities, livestock, forestry and disorderly tourism. Due to these impacts, there is a tendency to decrease local biodiversity by selection of more resistant species. This paper focuses the grassland community answers to mowing, grazing and tourism. In four sampling sites it was determined 107 taxa belonging to 23 botanic families. The main families are Asteraceae (24 taxa), Poaceae (24 taxa) and Fabaceae (14 taxa). Species diversity varied from 27 to 75 species. In relation to species number, non-grazed areas presented greater diversity than other ones; it points to that touristic visitation may cause lower impact than grazing or mowing. In spite of the anthropogenic factors, the focused sites presented high specific diversity in relation to related areas. In relation to species diversity, grazing or mowing are equal. Six genera presented potentiality as bioindicators of preserved environments: Croton, Galactia, Periandra, Cuphea, Pavonia, and Commelina, although more sample areas are necessary to reliable results.
\end{abstract}

Keywords: Grasslands; Campos Gerais; impacted area; grazing; touristic activities.

\section{INTRODUÇÃO}

A vegetação dos Campos Gerais do Paraná (MAACK, 1948) é composta por um mosaico de campos de altitude, relictos de cerrado e capões de Floresta com Araucária, que refletem na paisagem o equilíbrio atingido após a substituição de climas pretéritos mais secos do Pleistoceno pelas condições atuais úmidas do Holoceno (BEHLING, 1997, 1998).

A Estepe Gramíneo-Lenhosa (Instituto Brasileiro de Geografia e Estatística (IBGE) 1992) caracteriza-se pela predominância de espécies herbáceas em várias tipologias campestres, como estepe 
stricto sensu ou campo seco, estepe higrófila ou campo brejoso e refúgios vegetacionais rupestres, que compreendem os campos com afloramentos rochosos (ZILLER, 2002). Apresentando alto potencial biótico e uma exuberante riqueza de espécies, a região constitui reconhecidamente um hotspot, que demanda estratégias emergenciais para a sua conservação (MINISTÉRIO DO MEIO AMBIENTE/SECRETARIA DE BIODIVERSIDADE E FLORESTAS (MMA/SBF), 2002).

As formações vegetais campestres, em suas diversas fisionomias, vêm sofrendo forte pressão antrópica com a expansão das atividades agrícolas, pecuárias e silviculturais. Paralelamente, devido à sua grande beleza cênica, algumas regiões dos Campos Gerais são bastante procuradas para fins turísticos e recreativos. O estado atual de conservação dos campos no Paraná também resulta de processos históricos de uso e ocupação do solo, estando muito relacionado à expansão agropecuária, desde o ciclo do tropeirismo. Os remanescentes de campos nativos encontram-se, na sua maioria, em áreas de relevo acidentado, inviáveis à mecanização agrícola, sendo encontradas as porções menos fragmentadas dentro de Unidades de Conservação estaduais, como os parques de Vila Velha e Guartelá, e Federais, como o Parque Nacional dos Campos Gerais.

A integridade ecológica dos ecossistemas naturais em uma paisagem está diretamente relacionada com a manutenção das condições satisfatórias de qualidade ambiental da área (ALMEIDA; MORO, 2007). Dessa forma, é importante que a matriz seja conservada dentro de determinados limiares, a fim de garantir sua permeabilidade, proporcionando assim requisitos mínimos ao fluxo gênico das espécies. Um dos obstáculos à definição mais precisa desses limiares para as paisagens campestres no sul do Brasil é ainda a falta de dados acerca de sua composição florística sob diferentes condições de uso. Devido ao impacto gerado pelas atividades de visitação turística e pastejo por bovinos nos campos da região de Ponta Grossa, existe uma tendência à diminuição da biodiversidade local, pela seleção de espécies mais resistentes, deixando algumas porções de campo nativo com um aspecto rústico, em detrimento daquelas de hábitos mais restritivos. Esse trabalho pretende correlacionar a riqueza específica de áreas de campo nativo da região do Parque Nacional dos Campos Gerais às pressões antrópicas existentes.

\section{MATERIAIS E MÉTODOS}

\section{Caracterização da área de estudo}

O Parque Nacional dos Campos Gerais (PNCG), criado em 2006, abrange parte dos municípios de Ponta Grossa, Carambeí e Castro (UTM 7210000-7240000 e 590000-615000), com área aproximada de 21.288 ha, dividida em uma porção norte (18.103 ha) e outra porção sul (3.138 ha) (Figura 1). Está compreendido na zona de transição do Primeiro para o Segundo Planalto Paranaense, sendo que no Primeiro Planalto, a leste, abriga majoritariamente áreas florestais, e a oeste, no Segundo Planalto, abriga remanescentes campestres. Os campos nativos compreendidos em seus limites perfazem uma área aproximada de 6.935 ha, abrangendo alguns dos últimos remanescentes bem conservados da região. Os solos predominantes são Cambissolos e Neossolos Litólicos, desenvolvidos sobre rochas da Formação Furnas. A altitude média na região de estudo é de $980 \mathrm{~m}$, em um relevo que varia de suave ondulado a forte ondulado (DALAZOANA, 2010). Predomina, na região, clima $\mathrm{Cfb}$ de Köppen, com temperatura média anual de $17,6{ }^{\circ} \mathrm{C}$, variando entre $16{ }^{\circ} \mathrm{C}$ no mês mais frio e $22{ }^{\circ} \mathrm{C}$ no mês mais quente. A precipitação média anual da região varia entre 1.200 e $1.800 \mathrm{~mm}$, e a umidade relativa do ar entre 75 e 80\% (MELO et al., 2003).

Foram realizadas quatro amostragens em três áreas de campo nativo seco (estepe stricto sensu), todas localizadas no reverso da Escarpa Devoniana, município de Ponta Grossa (Figura 1). Todas as estações, segundo relatos dos moradores, possuem histórico de incêndios pouco frequentes, um a cada cinco anos ou menos.

A primeira estação de amostragem foi instalada na região das Furnas Gêmeas (FG), inserida na localidade de Passo do Pupo, em área de intensa visitação turística. As Furnas são crateras circulares de grande diâmetro, formadas por desabamentos doliniformes, e têm sua origem na estrutura falhada e fraturada da Formação Furnas. O interior das dolinas é ocupado por vegetação florestal típica da Floresta Ombrófila Mista e no seu entorno, acima, o campo nativo desenvolve-se entre os afloramentos de arenito. As gramíneas formam um estrato contínuo de aproximadamente $50 \mathrm{~cm}$ de altura. Nos locais em que a profundidade de solo permite, há presença de alguns capões de floresta com Araucaria angustifolia 
(ANDRADE et al., 2004). No entorno, a principal atividade econômica é a agricultura mecanizada, sem acesso de gado.

A segunda estação de amostragem foi localizada na Serrinha do São Jorge (SJ), próximo à ponte do Rio São Jorge. A análise foi realizada numa área de campo nativo submetido a pastejo bovino em sistema de pecuária extensiva, sem enriquecimento com forrageiras exóticas, prática comum na região. $\mathrm{O}$ campo apresentava-se como um estrato homogêneo de cerca de $20 \mathrm{~cm}$ de altura, e as gramíneas, apesar de abundantes, conservavam praticamente apenas seu sistema radicular, devido ao intenso pastejo a que são submetidas, o que dificulta sobremaneira sua identificação taxonômica.

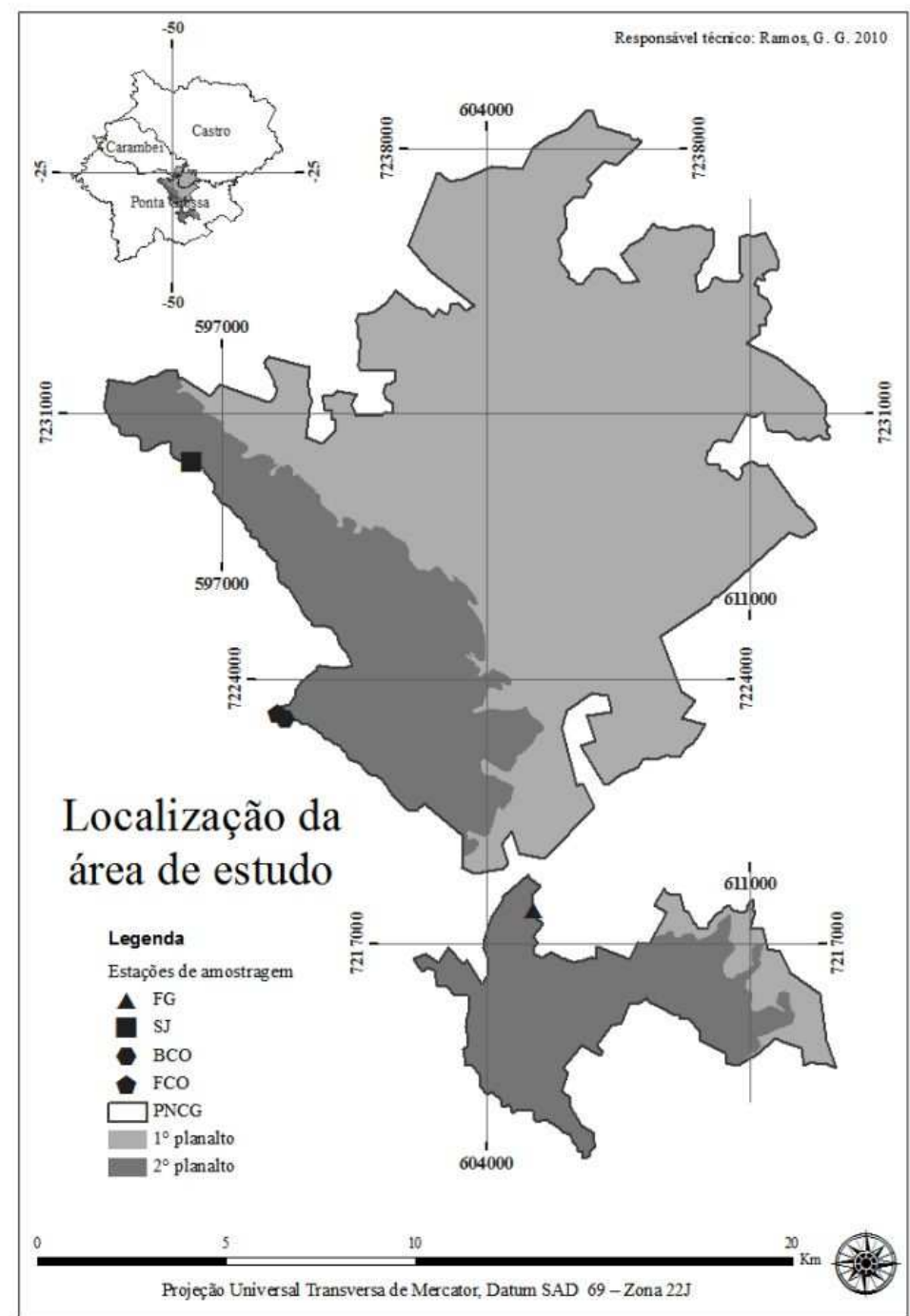

Figura 1. Localização das estações de amostragem no Parque Nacional dos Campos Gerais, Paraná. FG: Furnas Gêmeas; SJ: Serrinha São Jorge; BCO: Balneário Capão da Onça; FCO: Fazenda Capão da Onça.

Figure 1. Sampling sites in Campos Gerais National Park, Paraná. FG: Furnas Gêmeas; SJ: Serrinha São Jorge; BCO: Balneário Capão da Onça; FCO: Fazenda Capão da Onça.

A terceira estação de amostragem foi instalada no balneário Capão da Onça (BCO), um local de ampla visitação turística, nas margens do Rio Verde (MARQUES; MORO, 2001). Predomina campo nativo, relativamente bem conservado apesar de sofrer pisoteio de modo esporádico, com um estrato graminoide de aproximadamente $40 \mathrm{~cm}$ de altura. Muitas espécies com hábito arbustivo foram observadas 
apenas sob a forma de plântulas, o que pode ser devido à prática da roçada no período de verão pelos mantenedores do local. No seu entorno desenvolvem-se atividades agropecuárias, principalmente a criação de gado de corte e plantios anuais. A quarta estação, Fazenda Capão da Onça (FCO), localiza-se numa propriedade desse entorno, com pastejo por bovinos em sistema de pecuária extensiva, sem enriquecimento com forrageiras exóticas. O campo apresenta um aspecto bastante degradado, com estrato herbáceo não ultrapassando $20 \mathrm{~cm}$, gramíneas pastejadas e presença de ruderais.

\section{Procedimento metodológico}

Foram realizadas oito transecções, duas em cada estação de amostragem, de janeiro a abril de 2009. Como todas as rampas apresentavam leve inclinação, uma transecção foi instalada cortando o sentido da vertente e outra perpendicular à anterior, partindo do $3^{\circ}$ metro da mesma (Figura 2), no terço superior da rampa, sobre solos não hidromórficos.

As transecções foram graduadas em metros e a coleta das plantas tocadas pelo transecto ocorreu de modo que, a cada metro, eram anotadas apenas as espécies inéditas que ocorriam naquele ambiente. As plantas foram herborizadas e posteriormente identificadas no Herbário da Universidade Estadual de Ponta Grossa (HUPG), conforme o sistema de classificação APG II (Angiosperm Philogeny Group). As floridas ou frutificadas foram incorporadas ao acervo do herbário.

A suficiência amostral foi testada de acordo com Müller-Dombois; Ellemberg (1974), por meio da curva do coletor, com ajuste da curva real por regressão logarítmica múltipla. O valor médio da suficiência amostral foi obtido através da média aritmética entre as duas transecções em cada estação. As frequências de espécies e valores de suficiência amostral foram testados pelo Chi-quadrado. Uma análise de agrupamento foi utilizada para investigar a similaridade entre os grupos de plantas de cada estação de coleta. Os gráficos e análises foram gerados pelos softwares BioEstat e Statistica for Windows®.

\section{Orientação das Transecções}

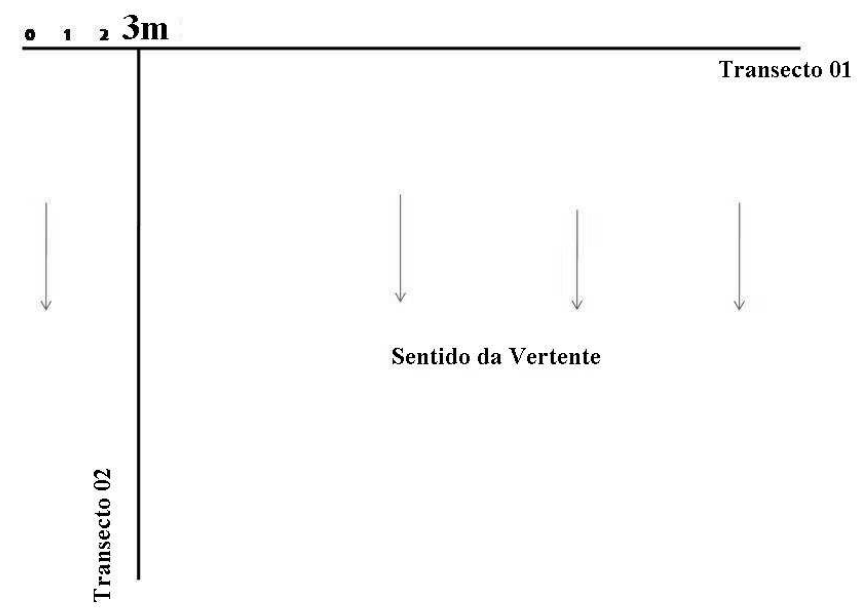

Figura 2. Orientação das transecções em cada estação de coleta no Parque Nacional dos Campos Gerais. Figure 2. Transects orientation in each sampling site in Campos Gerais National Park.

\section{RESULTADOS E DISCUSSÃO}

Ao todo foram determinadas 107 espécies distribuídas em 23 famílias botânicas, além de três espécies indeterminadas a qualquer nível (Tabela 1). As famílias com maior riqueza específica foram Asteraceae e Poaceae, ambas com 24 espécies, e Fabaceae, com 14 espécies.

Com relação a estudos realizados em áreas de campo nativo semelhantes, poupadas do fogo, Novochadlo (2005), para três transectos de estepe stricto sensu no Parque Estadual de Vila Velha, registrou 32 espécies, das quais oito eram Asteraceae e oito eram Poaceae. Dalazoana et al. (2007), 
também em Vila Velha, através de oito transectos, identificaram 69 táxons, distribuídos em 26 famílias botânicas, das quais as mais representativas foram Asteraceae (com 14 espécies) e Poaceae (10 espécies). No Parque Estadual do Guartelá, Carmo (2006), por meio de 30 parcelas em campo seco, identificou 80 espécies distribuídas em 15 famílias, sendo Poaceae e Asteraceae as famílias mais importantes em riqueza de espécies, com 29 e 15 táxons, respectivamente.

Tabela 1. Lista das espécies amostradas em Furnas Gêmeas (FG), Serrinha do São Jorge (SJ), Balneário Capão da Onça (BCO) e Fazenda Capão da Onça (FCO). Os algarismos 0 e 1 indicam, respectivamente, ausência e presença das espécies.

Table 1. List of species at Furnas Gêmeas (FG), Serrinha do São Jorge (SJ), Balneário Capão da Onça (BCO) and Fazenda Capão da Onça (FCO). The digits 0 and 1 indicate absence and presence of the species respectively.

\begin{tabular}{|c|c|c|c|c|c|}
\hline \multirow[t]{2}{*}{ Família } & \multirow[t]{2}{*}{ Espécie } & \multicolumn{4}{|c|}{$\begin{array}{c}\text { Estações de amostragem - } \\
\text { Ocorrência }\end{array}$} \\
\hline & & FG & SJ & BCO & FCO \\
\hline Amaranthaceae & Alternanthera brasiliana (L.) Kuntze & 1 & 0 & 0 & 0 \\
\hline \multirow[t]{2}{*}{ Apiaceae } & Eryngium junceum Cham. & 0 & 0 & 0 & 1 \\
\hline & Hydrocotyle asiatica $\mathrm{L}$. & 1 & 0 & 0 & 1 \\
\hline Arecaceae & Allagoptea campestris Buri & 1 & 0 & 0 & 0 \\
\hline \multirow[t]{24}{*}{ Asteraceae } & Achyrocline satureioides (Lam.) DC. & 1 & 0 & 0 & 0 \\
\hline & Aspilia setosa Griseb & 1 & 0 & 1 & 1 \\
\hline & Aspilia montevidensis (Spr.) Kuntze & 1 & 0 & 0 & 0 \\
\hline & Baccharis coridifolia DC. & 1 & 1 & 1 & 0 \\
\hline & Baccharis crispa Spr. & 1 & 1 & 1 & 1 \\
\hline & Baccharis dracunculifolia DC. & 1 & 0 & 1 & 0 \\
\hline & Baccharis myricaefolia DC. & 0 & 1 & 0 & 0 \\
\hline & Calea hispida (DC.) Bak. & 1 & 0 & 1 & 0 \\
\hline & Erigeron bonariensis L. & 1 & 0 & 0 & 0 \\
\hline & Eupatorium congestum Hook. et Arn. & 1 & 1 & 1 & 1 \\
\hline & Eupatorium orbiculatum DC. & 0 & 0 & 1 & 0 \\
\hline & Eupatorium sp. & 1 & 0 & 0 & 0 \\
\hline & Heterothalamus psiadioides Less. & 1 & 1 & 1 & 1 \\
\hline & Lucilia lycopodioides (Less.) SE Freire & 0 & 0 & 0 & 1 \\
\hline & Senecio sp. & 1 & 0 & 0 & 0 \\
\hline & Solidago chilensis Meyen & 1 & 0 & 0 & 0 \\
\hline & Stevia clausenii Shultz-Bip. & 0 & 0 & 0 & 1 \\
\hline & Vernonia crassa Ehman ex Malme. & 1 & 0 & 0 & 0 \\
\hline & Vernonia glabrata Less. & 1 & 0 & 0 & 0 \\
\hline & Vernonia rigiophylla Sch. Bip. ex Baker & 0 & 1 & 1 & 1 \\
\hline & Vernonia sp. 1 & 0 & 0 & 1 & 0 \\
\hline & Vernonia sp. 2 & 0 & 0 & 1 & 0 \\
\hline & Asteraceae 1 & 1 & 1 & 1 & 1 \\
\hline & Asteraceae 2 & 1 & 1 & 0 & 1 \\
\hline Campanulaceae & Wahlenbergia linarioides (Lam.) A.DC. & 1 & 0 & 0 & 0 \\
\hline \multirow[t]{2}{*}{ Commelinaceae } & Commelina difusa Burm. f. & 1 & 0 & 0 & 0 \\
\hline & Commelina villosa C.B. Clarke & 1 & 0 & 0 & 0 \\
\hline Convolvulaceae & Convolvulaceae 1 & 0 & 0 & 1 & 0 \\
\hline Cuscutaceae & Cuscuta racemosa Mart. et Humb. & 1 & 0 & 0 & 1 \\
\hline \multirow[t]{5}{*}{ Cyperaceae } & Cyperus brevifolius (Rottb.) Hassk. & 1 & 0 & 0 & 0 \\
\hline & Cyperus cayanensis (Lam.) Britton & 1 & 0 & 0 & 0 \\
\hline & Cyperus flavus (Vahl.) Nees & 1 & 1 & 1 & 1 \\
\hline & Cyperus sesquiflorus (Torrey) Mattf et Kuk. & 1 & 0 & 1 & 0 \\
\hline & Rhynchospora corymbosa (L.) Britton & 0 & 1 & 1 & 1 \\
\hline Dennstaedtiaceae & Pteridium arachnoideum (Kaulfuss) Maxon & 1 & 0 & 1 & 0 \\
\hline
\end{tabular}

FLORESTA, Curitiba, PR, v. 41, n. 2, p. 387-396, abr./jun. 2011. 


\begin{tabular}{|c|c|c|c|c|c|}
\hline \multirow[t]{3}{*}{ Euphorbiaceae } & Croton heterodoxus Bail. & 1 & 0 & 0 & 0 \\
\hline & Euphorbia sp. & 0 & 0 & 1 & 0 \\
\hline & Sebastiania hispida (Mart.) Pax & 0 & 1 & 0 & 0 \\
\hline \multirow[t]{15}{*}{ Fabaceae } & Aeschynomene falcata (Poir) DC. & 1 & 1 & 1 & 0 \\
\hline & Crotalaria hilariana Benth. & 0 & 0 & 1 & 1 \\
\hline & Desmodium adscendens (Sw.) DC. & 1 & 1 & 1 & 1 \\
\hline & Desmodium incanum (Sw.) DC. & 1 & 0 & 1 & 1 \\
\hline & Eriosema campestre var. macrophyllum (Grear) Fort. & 0 & 0 & 1 & 0 \\
\hline & Eriosema glabrum Mart. ex Benth. & 0 & 1 & 1 & 0 \\
\hline & Eriosema heterophyllum Benth. & 1 & 0 & 1 & 0 \\
\hline & Eriosema longifolium Benth. & 0 & 1 & 1 & 1 \\
\hline & Galactia boavista (Vell.) Burk. & 1 & 0 & 0 & 0 \\
\hline & Mimosa dolens (Benth.) Barn. & 1 & 0 & 1 & 1 \\
\hline & Periandra mediterranea (Vell.) Taub. & 1 & 0 & 0 & 0 \\
\hline & Stylosanthes hyppocampoides Mohembrock & 1 & 1 & 1 & 1 \\
\hline & Zornia diphylla Pers. & 1 & 1 & 1 & 1 \\
\hline & Fabaceae 1 & 1 & 0 & 1 & 0 \\
\hline & Fabaceae 2 & 0 & 0 & 1 & 1 \\
\hline Iridaceae & Sisyrinchium restioides $\mathrm{Spr}$. & 1 & 0 & 1 & 1 \\
\hline \multirow[t]{2}{*}{ Lamiaceae } & Peltodon longipes A. St.-Hil. ex Benth. & 1 & 1 & 1 & 1 \\
\hline & Salvia sp. & 0 & 1 & 0 & 0 \\
\hline \multirow[t]{3}{*}{ Lythraceae } & Cuphea calophylla Cham. et Schl. & 1 & 0 & 0 & 0 \\
\hline & Cuphea lindmaniana Koehne ex Bac. & 1 & 0 & 0 & 0 \\
\hline & Cuphea linarioides Cham. et Schl. & 0 & 0 & 0 & 1 \\
\hline \multirow[t]{2}{*}{ Malphigiaceae } & Aspicarpa pulchella (Griseb) O'Donell et Lourteig & 1 & 1 & 1 & 0 \\
\hline & Byrsonima intermedia Juss. & 0 & 0 & 1 & 0 \\
\hline \multirow[t]{3}{*}{ Malvaceae } & Pavonia speciosa H.B.K. & 1 & 0 & 0 & 0 \\
\hline & Sida macrodon DC. & 1 & 1 & 1 & 1 \\
\hline & Sida spinosa $\mathrm{L}$. & 1 & 0 & 0 & 0 \\
\hline Melastomataceae & Tibouchina gracilis (Bonpl.) Cogn. & 1 & 1 & 0 & 0 \\
\hline \multirow[t]{4}{*}{ Myrtaceae } & Eugenia bimarginata DC. & 0 & 1 & 0 & 0 \\
\hline & Eugenia obversa O. Berg. & 1 & 0 & 0 & 0 \\
\hline & Psidium sp. & 1 & 0 & 0 & 0 \\
\hline & Myrtaceae 1 & 1 & 0 & 0 & 0 \\
\hline Oxalidaceae & Oxalys sp. & 0 & 0 & 1 & 0 \\
\hline Plantaginaceae & Plantago guilleminiana Decne & 0 & 0 & 0 & 1 \\
\hline \multirow[t]{18}{*}{ Poaceae } & Andropogon bicornis L. & 1 & 0 & 0 & 1 \\
\hline & Andropogon leuchostachyus H.В.K. & 1 & 0 & 0 & 0 \\
\hline & Aristida flaveola $\mathrm{L}$. & 1 & 0 & 0 & 0 \\
\hline & Aristida jubata $\mathrm{L}$. & 0 & 1 & 1 & 1 \\
\hline & Axonopus siccus (Nees) Kuhlm & 1 & 0 & 1 & 0 \\
\hline & Brachiaria fasciculata (Sw.) Parodi & 1 & 0 & 1 & 0 \\
\hline & Calamagrostis viridiflavescens (Poir.) Stroedel & 1 & 0 & 0 & 0 \\
\hline & Chloris gayana Kunth & 1 & 0 & 0 & 0 \\
\hline & Eragrostis airoides Nees & 1 & 0 & 0 & 0 \\
\hline & Eragrostis pilosa (L.) Beav. & 1 & 0 & 0 & 1 \\
\hline & Hypogynium virgatum (Desv.) Dandy & 0 & 0 & 1 & 0 \\
\hline & Paspalum dilataum Poir. & 1 & 0 & 1 & 1 \\
\hline & Paspalum maritimum Trin. & 1 & 0 & 0 & 0 \\
\hline & Paspalum rhodopedum L.B. Smith et Wassausen & 0 & 1 & 0 & 0 \\
\hline & Pennisetum clandestinum Hachsct. & 1 & 0 & 0 & 0 \\
\hline & Pseudochinolaena sp. & 0 & 0 & 1 & 0 \\
\hline & Melinis repens (Willd) G. Ziska & 1 & 0 & 0 & 1 \\
\hline & Setaria geniculata (Lam.) Beauv. & 1 & 0 & 0 & 0 \\
\hline
\end{tabular}




\begin{tabular}{|c|c|c|c|c|c|}
\hline & Setaria sp. & 1 & 0 & 1 & 0 \\
\hline & Trachypogon spicatus (L.f.) Kuntze & 1 & 1 & 1 & 0 \\
\hline & Trachypogon sp. & 1 & 0 & 1 & 0 \\
\hline & Poaceae 1 & 1 & 0 & 1 & 1 \\
\hline & Poaceae 2 & 1 & 0 & 0 & 0 \\
\hline & Poaceae 3 & 1 & 0 & 0 & 0 \\
\hline \multirow[t]{3}{*}{ Rubiaceae } & Borreria poaya (St.-Hill.) DC. & 1 & 1 & 1 & 1 \\
\hline & Relbunium megapotamium (Spr.) Ehrendf & 1 & 1 & 1 & 0 \\
\hline & Rubiaceae 1 & 0 & 0 & 1 & 1 \\
\hline \multirow[t]{2}{*}{ Verbenaceae } & Verbena hirta Spr. & 0 & 0 & 0 & 1 \\
\hline & Verbenaceae 1 & 1 & 0 & 0 & 0 \\
\hline \multirow[t]{3}{*}{ Indeterminadas } & Indet 1 & 0 & 0 & 0 & 1 \\
\hline & Indet 2 & 1 & 0 & 0 & 0 \\
\hline & Indet 3 & 0 & 0 & 0 & 1 \\
\hline
\end{tabular}

Para locais fora de unidades de conservação, na região de Balsa Nova, com histórico de fogo e pastejo não declarados, Langohr (1992), analisando 400 pontos em cinco transectos, registrou 59 espécies para um campo limpo, enquanto Kozera (2008), utilizando parcelas, registrou 428 espécies em um campo mesófilo, apontando-se Asteraceae (com 40 espécies), Poaceae (26) e Cyperaceae (19) como as famílias mais representativas.

Portanto, as áreas neste estudo apresentaram uma elevada riqueza específica, composta por famílias apontadas como sendo típicas desses ambientes campestres, mesmo levando em conta as diferenças metodológicas entre os trabalhos efetuados na região.

Comparando-se a riqueza de espécies entre as estações (Figura 3), as áreas não pastejadas FG e $\mathrm{BCO}$ apresentaram maior riqueza específica em relação àquelas submetidas ao pastejo, SJ e FCO. Na estação de Furnas Gêmeas (FG) foram registradas 75 espécies, sendo 37 exclusivas desse local, e a suficiência amostral foi alcançada ao longo de $21 \mathrm{~m}$ de transecto. Na estação Balneário Capão da Onça (BCO) foram registradas 52 espécies, sendo 10 exclusivas, e a suficiência amostral foi alcançada em $11 \mathrm{~m}$, aproximadamente.

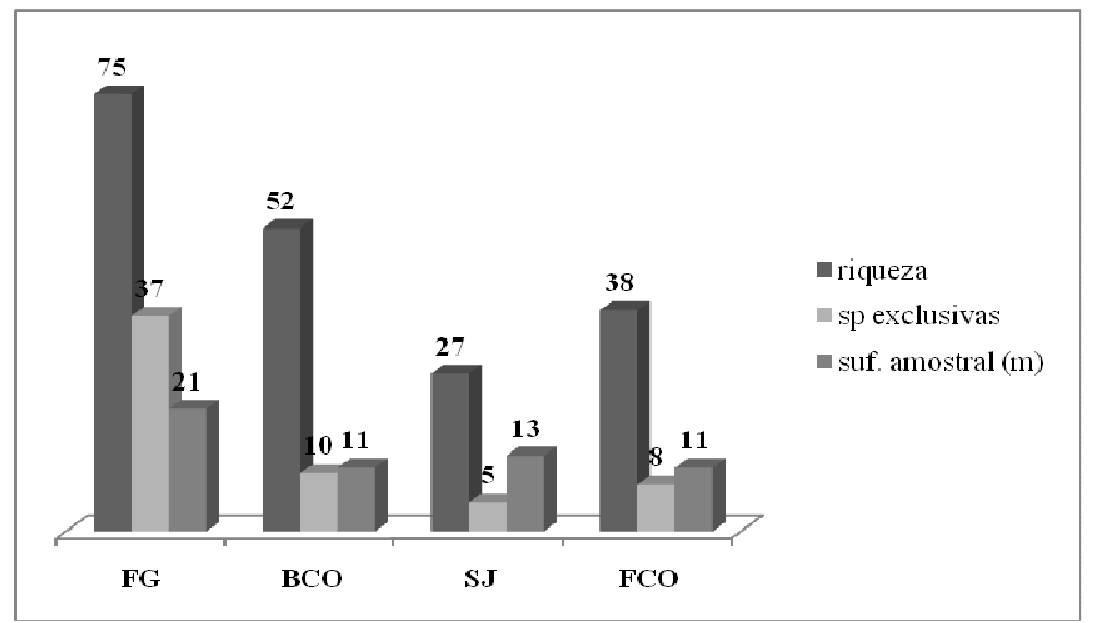

Figura 3. Riqueza, espécies exclusivas e suficiência amostral nos campos do Parque Nacional dos Campos Gerais, PR. FG: Furnas Gêmeas; BCO: Balneário Capão da Onça; SJ: Serrinha do São Jorge; FCO: Fazenda Capão da Onça.

Figure 3. Species richness and sufficiency sampling in the grasslands of Campos Gerais National Park, PR. FG: Furnas Gêmeas; BCO: Balneário Capão da Onça; SJ: Serrinha do São Jorge; FCO: Fazenda Capão da Onça.

Na estação de coleta Serrinha do São Jorge (SJ) foram registradas 27 espécies, sendo cinco exclusivas, e a suficiência amostral foi alcançada em 13 metros. Na estação Fazenda Capão da Onça

FLORESTA, Curitiba, PR, v. 41, n. 2, p. 387-396, abr./jun. 2011.

Dalazoana, K.; Moro, R. S. 
(FCO) foram registradas 38 espécies, com oito exclusivas, e a suficiência amostral foi atingida ao longo de 11 metros.

A maior riqueza específica de FG, quando comparada às demais estações, pode ser creditada ao baixo nível de impacto sofrido pela vegetação campestre, pela ausência de sistemas produtivos e de fogo, apenas suscetível ao pisoteio por visitantes. A suficiência amostral tendeu a ser atingida mais tarde nessa área sem pastejo nem roçada, embora não tenha havido diferença significativa entre a suficiência amostral e as frequências de espécies obtidas nas quatro estações de coleta $(p=0,36)$. Portanto, a estimativa da suficiência amostral pela curva do coletor refletiu a proporcionalidade da riqueza específica entre as estações. Com relação à riqueza e número de espécies exclusivas, as estações diferiram significativamente $(\mathrm{p}=0,03)$, apontando para distintas variáveis interferindo nessa distribuição.

Quando as estações foram comparadas em termos de similaridade florística (Figura 4), a estação FG compôs um grupo a parte $(\mathrm{p}=0,03)$, fato devido à sua maior riqueza de espécies em comparação às demais estações de coleta, bem como ao grande número de espécies exclusivas. O segundo grupo, incluindo as demais estações, pode ser considerado floristicamente similar $(p=0,97)$, envolvendo espécies aparentemente mais resistentes à pressão seletiva das variáveis pastejo e roçada.

\section{Similaridade Florística \\ Método de Ward \\ Distância Euclidiana}

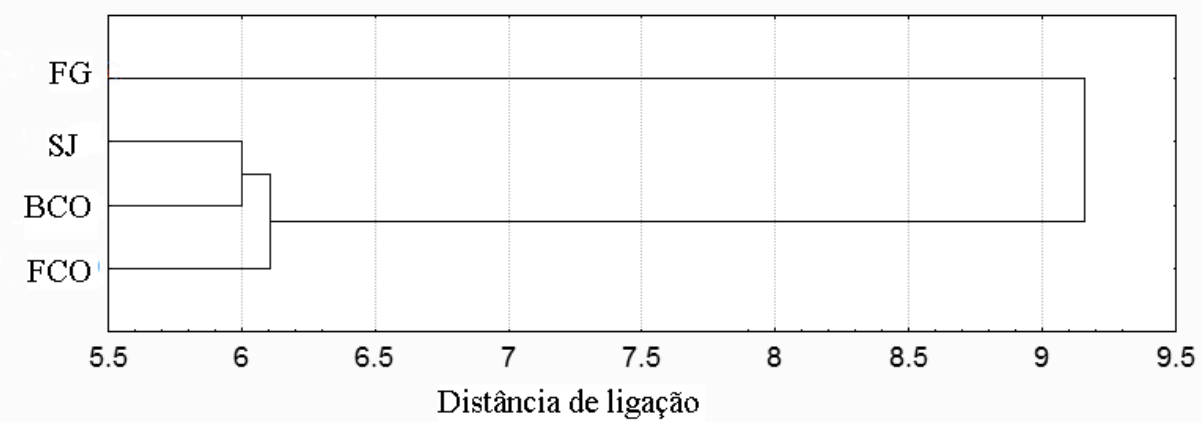

Figura 4. Similaridade florística entre as estações no Parque Nacional dos Campos Gerais, PR. Figure 4. Floristic similarity among grasslands in the National Park of Campos Gerais, PR.

Dos 24 táxons de Poaceae registrados neste estudo, 20 estavam presentes na estação FG (não pastejada), mas apenas três puderam ser reconhecidos na estação SJ (pastejada), apontando a alta seletividade dos herbívoros para essa família. Croton, Galactia, Periandra, Cuphea, Pavonia, Commelina e algumas Myrtaceae, presentes apenas na estação FG, podem ser consideradas indicadores de ambientes bem conservados, livres de gado e roçada. Outros táxons bastante comuns na região, considerados mesmo como ruderais - Achyrocline satureioides, Pennisetum clandestinum, Melinis repens e Solidago chilensis , estiveram também presentes apenas na estação FG. Não foi possível observar se sua ausência nas demais estações era total ou apenas da parte aérea. Isso pode apontar o fato de elas também serem alvos preferenciais de herbivoria, além de sensíveis a roçada periódica na estação BCO.

Dez espécies - Baccharis crispa, Eupatorium congestum, Heterothalamus psiadioides, Cyperus flavus, Desmodium adscendens, Stylosanthes hyppocampoides, Zornia diphylla, Peltodon longipes, Sida macrodon e Borreria poaya - estiveram presentes em todas as estações, demonstrando ter pouco valor na bioindicação de impactos por pisoteio ou pastejo.

\section{CONCLUSÕES}

- O levantamento mostrou que, apesar da forte pressão antrópica a que são submetidas, as áreas estudadas exibem considerável riqueza de espécies quando comparadas a outros trabalhos na região, mantendo ainda seu potencial biótico dinâmico. Em termos de número de espécies, a área turística 
não pastejada apresenta maior riqueza em relação àquelas submetidas ao pastejo ou à roçada. Floristicamente, estas últimas formam uma unidade significativa que permite concluir que o impacto por gado ou por manejo com roçadeira se equivalem.

- A visitação turística revelou ser bem menos impactante do que a criação de gado, desde que as áreas não sejam roçadas. A família Poaceae é a mais severamente afetada na redução de riqueza em função da herbivoria ou roçada. Seis gêneros têm potencial para serem utilizados como bioindicadores de áreas conservadas (Croton, Galactia, Periandra, Cuphea, Pavonia e Commelina), mas há necessidade de ampliação das áreas estudadas para estabelecer mais claramente seu valor de bioindicação.

- Dada a importância ecológica dos ecossistemas locais, é necessário que haja o manejo das áreas de campo nativo, com o intuito de promover a sua regeneração natural, prevenindo a supressão da parte aérea e assegurando a preservação das espécies vegetais, de modo a minimizar as pressões antrópicas exercidas e a consequente perda de biodiversidade.

\section{AGRADECIMENTOS}

À Fundação Araucária de Desenvolvimento Científico, pela concessão da Bolsa de Mestrado em Gestão do Território; à Companhia Paranaense de Energia Elétrica (COPEL) e à Companhia de Saneamento do Paraná (SANEPAR), pelo suporte operacional.

\section{REFERÊNCIAS}

ALMEIDA, C. G.; MORO, R. S. Análise da cobertura florestal no Parque Nacional dos Campos Gerais, Paraná, como subsídio ao seu plano de manejo. Rev. Terr@ Plural. v. 1, n. 1, p. 115 - 122, 2007.

ANDRADE, A. L. P.; SANTOS, G. A. S. D. dos; CAMPOS, K. A.; CARMO, M. R. B. do. Levantamento florístico da região das Furnas Gêmeas, município de Ponta Grossa, Estado do Paraná. In: ENCONTRO DE PESQUISA DA UEPG, 4, Ponta Grossa, 2004. Resumos... 1 CD-ROM.

BEHLING, H. Late Quaternary vegetation, climate and fire history in the Araucaria forest and campos region from Serra Campos Gerais (Paraná), South Brazil. Rev. Paleobot. Palynol., v. 97, p. 109 - 121 , 1997.

BEHLING, H. Late Quaternary vegetational and climatic changes in Brazil. Rev. Paleobot. Palynol., v. 99, p. 143 - 156, 1998.

CARMO, M. R. B. do. Caracterização fitofisionômica do Parque Estadual do Guartelá, município de Tibagi, Estado do Paraná. Tese (Doutorado em Biologia Vegetal) - Instituto de Biociências, Universidade Estadual Paulista. Rio Claro, 2006.

DAlAZOANA, K.; RITTER, L. M. O.; SILVA, M. A.; MORO, R. S. Caracterização dos campos naturais do Parque Estadual de Vila Velha, Ponta Grossa PR. In: ENCONTRO DE PESQUISA,., 2007, Ponta Grossa, ENCONTRO DE EXTENSÃO DA UNIVERSIDADE ESTADUAL DE PONTA GROSSA, 8, 5., 2007, Ponta Grossa. Resumos..., Ponta Grossa, 2010

DALAZOANA, K. Espacialização dos campos nativos na Escarpa Devoniana do Parque Nacional dos Campos Gerais, Paraná. Ponta Grossa, 2010. Dissertação (Mestrado em Gestão do Território) Universidade Estadual de Ponta Grossa. Disponível em http://www.bicen-tede.uepg.br/tde_busca/arquivo. php?codArquivo=486.

INSTITUTO BRASILEIRO DE GEOGRAFIA E ESTATÍSTICA (IBGE). Manual de classificação da vegetação brasileira. Série Man. Téc. em Geociências. Rio de Janeiro. n. 1. 1992.92 p.

KOZERA, C. Florística e fitossociologia de uma formação pioneira com influência fluvial e de uma estepe gramíneo-lenhosa em diferentes unidades geopedológicas, município de Balsa Nova, Paraná, Brasil. Tese (Doutorado em Conservação da Natureza) - Universidade Federal do Paraná, 2008. 
LANGOHR, I. M. Estudo fitossociológico de um campo limpo localizado em Felipe da Cancela, município de Balsa Nova, Paraná, Brasil. 32 p. Monografia (Bacharelado em Biologia) - Pontifícia Universidade Católica do Paraná, Curitiba. 1992.

MAACK, R. Notas preliminares sobre clima, solos e vegetação do Estado do Paraná. Arquivos de Biologia e Tecnologia, v. 2, p. 102-200, 1948.

MARQUES, S. H. P.; MORO, R. S. Checklist preliminar da vegetação fanerogâmica do Capão da Onça, Ponta Grossa, PR. In: ENCONTRO REGIONAL DE BOTÂNICOS DO PARANÁ E SANTA CATARINA, 6, Curitiba, 2001. Resumos... Curitiba, 2001. p. 112.

MELO, M. S.; MATIAS, L. F. (orgs.) Patrimônio Natural dos Campos Gerais. Ponta Grossa: UEPG, 2003. Disponível em: http://www.uepg.br/natural.

MINISTÉRIO DO MEIO AMBIENTE/SECRETARIA DE BIODIVERSIDADE E FLORESTAS (MMA/SBF) -. Biodiversidade brasileira: avaliação e identificação de áreas e ações prioritárias para conservação, utilização sustentável e repartição dos benefícios da biodiversidade nos biomas brasileiros. Brasília, 2002. 404 p. Disponível em: http://www.mma.gov.br/probio/publicações/biodiversidade5.

MUELLER-DOMBOIS, D.; ELLENBERG, H. Aims and methods of vegetation ecology. New York: John Wiley and Sons, 1974.

NOVOCHADLO, T. H. Estrutura de comunidades de duas áreas de campo no parque Estadual de Vila Velha, Ponta Grossa, PR. Monografia (Bacharelado em Biologia) - Universidade Estadual de Ponta Grossa, Ponta Grossa, 2005.

ZILLER, S. R.; GALVÃO, F. O processo de degradação da Estepe Gramíneo-Lenhosa no Paraná por contaminação biológica de Pinus elliotti e P. taeda. Floresta, v. 32, n. 1, p. 41 - 47, 2002. 